\title{
An Episodic Weakening in the Boreal Spring SST-Precipitation Relationship in the Western Tropical Pacific since the Late 1990s
}

\author{
HYUN-SU JO \\ Commonwealth Scientific and Industrial Research Organisation (CSIRO) Oceans and Atmosphere, Aspendale, \\ Victoria, Australia \\ SANG-WOOK YEH \\ Department of Marine Sciences and Convergent Technology, Hanyang University, ERICA, Ansan, South Korea

\section{WENJU CAI} \\ Key Laboratory of Physical Oceanography/Institute for Advanced Ocean Studies, Ocean University of China \\ and Qingdao National Laboratory for Marine Science and Technology, Qingdao, China, and Centre for \\ Southern Hemisphere Oceans Research, Commonwealth Scientific and Industrial Research Organisation \\ (CSIRO) Oceans and Atmosphere, Hobart, Australia
}

(Manuscript received 31 October 2017, in final form 22 March 2019)

\begin{abstract}
We found that a positive sea surface temperature (SST)-precipitation relationship in the western tropical Pacific (WTP) during boreal spring, in which higher SSTs are associated with higher precipitation, episodically weakens from the late 1990s to the early 2010s. During 1980-98, warm SSTs induce positive precipitation and low pressure in the WTP. The associated enhanced convection dampens the initial warm SSTs by reflecting incoming solar radiation. The reduced incoming solar radiation into the ocean leads to a SST cooling tendency. In contrast, the associated southwesterly wind anomalies reduce oceanic mixing by decreasing the mean wind, contributing to an SST warming tendency, though relatively small. Therefore, the cloud-radiation effect is a dominant process of the negative SST tendency. By contrast, during 1999-2014, although an SST cooling tendency is similarly induced by warm SST anomalies, the cooling tendency is enhanced by anomalous ocean advection, as a result of enhanced easterly wind anomalies in the southern part of the WTP. This results in a weakening of a positive relationship of the SST and precipitation during 1999-2014. As such, the associated anomalous convective heating in the WTP during 1999-2014 is weak, changing the atmospheric teleconnection patterns in the midlatitude and surface air temperature anomalies in western North America and northeastern Eurasia.
\end{abstract}

\section{Introduction}

Ocean-atmosphere interactions play an important role in modifying precipitation variability in the western tropical Pacific (WTP) $\left(0^{\circ}-15^{\circ} \mathrm{N}, 130^{\circ}-150^{\circ} \mathrm{E}\right.$; see Fig. 1, black box), where the sea surface temperatures (SSTs) exceed $28^{\circ} \mathrm{C}$ (Fig. 1a) (Wu and Kirtman 2007; Kim et al. 2009; Wu et al. 2009; Lu and Lu 2014; Jang et al. 2016; He et al. 2017). The associated precipitation variability has pronounced impacts on East Asian and East African climate via atmospheric teleconnections (Nitta 1987; Huang and Sun 1992; Wang et al. 2001; Wang et al. 2003; Lee et al. 2006; Yim et al. 2008;

Corresponding author: Prof. Sang-Wook Yeh, swyeh@hanyang. ac.kr
Lyon and DeWitt 2012; Chang et al. 2014). In addition, tropical ocean-atmosphere interactions have implications for predictability, as well as prediction skill, of precipitation on monthly and seasonal time scales (Wu et al. 2006; Chang et al. 2011; Kumar et al. 2013, Jo et al. 2015). In light of this, an investigation of ocean-atmosphere interactions in the WTP is particularly useful.

Wu et al. (2006) used simultaneous correlations between precipitation and either SSTs or SST tendencies to examine the associated ocean-atmosphere interactions. For example, warm SST anomalies induce stronger convection, increasing evaporation, low-level moisture, and precipitation, leading to a positive relationship between SST and precipitation. On the other hand, stronger atmospheric convection, in turn, leads to cool SST anomalies 
(a) Clim. SST [MAM]

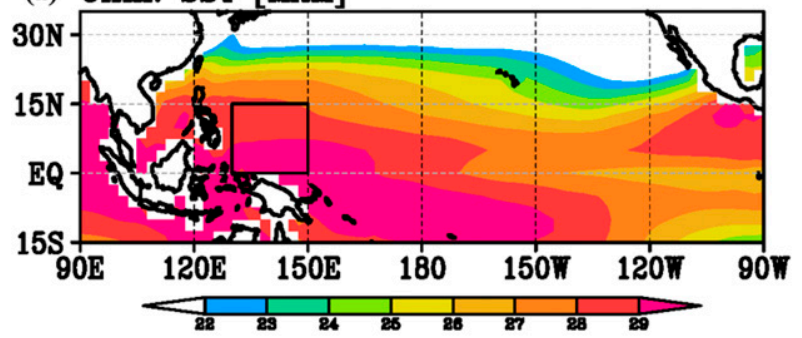

(b) Clim. Precip. \& $1000 \mathrm{hPa}$ Wind [MAM]

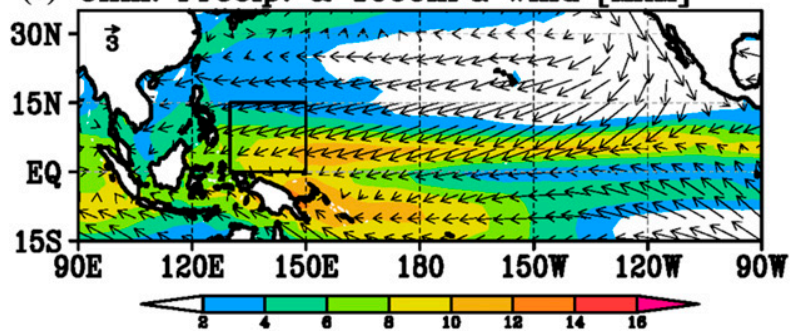

FIG. 1. (a) Climatological SST $\left({ }^{\circ} \mathrm{C}\right)$ for $1980-2017$ during boreal spring (MAM). (b) As in (a), but for precipitation (shading; $\mathrm{mm} \mathrm{day}^{-1}$ ) and $1000-\mathrm{hPa}$ winds (vectors; $\mathrm{m} \mathrm{s}^{-1}$ ). The black box indicates the western tropical Pacific region (WTP; $0^{\circ}-15^{\circ} \mathrm{N}, 130^{\circ}-$ $150^{\circ} \mathrm{E}$ ) in this study.

by increasing cloud, wind-induced oceanic mixing/upwelling, or the wind-evaporation effect. According to a previous study, interannual variability of precipitation over the tropical Pacific, defined as a leading mode during boreal spring, experienced a distinct interdecadal change before and after 1998, related to a negative phase of the Pacific decadal oscillation (Guo et al. 2016). Their results indicate that boreal spring ocean-atmosphere interactions in the WTP change on decadal time scales. However, the physical processes and associated atmospheric teleconnections have not yet been well understood. In this study, we find that a positive SST-precipitation relationship in the WTP during March-May (MAM) weakens from the late 1990s to the early 2010s, and we examine the associated mechanisms.

The remainder of the paper is outlined as follows. In section 2, observational datasets and methods used in this study are summarized. In section 3 , we present physical processes responsible for the weakening of the SSTprecipitation relationship in the WTP during MAM. In section 4, the different atmospheric teleconnection patterns and climate impacts between the two periods are shown. Finally, a summary is given in section 5 .

\section{Data and methods}

Monthly precipitation data were obtained from the Climate Prediction Center (CPC) Merged Analysis of Precipitation (CMAP; Xie and Arkin 1997) and ERA-
Interim (Dee et al. 2011). Monthly mean SST data from the Extended Reconstructed Sea Surface Temperature version 5 (ERSSTv5; Huang et al. 2015) and ERAInterim were used.

Surface heat fluxes (shortwave, longwave, latent heat, and sensible heat), sea level pressure (SLP), total cloud cover, 2-m air temperature, and 200-hPa geopotential height were obtained from ERA-Interim. The oceanic data for potential temperature, ocean currents, vertical velocity, and wind stress were obtained from the NCEP Global Ocean Data Assimilation System (GODAS) (Behringer and Xue 2004). Diabatic heating data were obtained from the National Centers for Environmental Prediction (NCEP)-Department of Energy (DOE) Reanalysis 2 for the available years of 1979-2013 (Kanamitsu et al. 2002). Diabatic heating data were partitioned into six components: large-scale condensation, deep convective, shallow convective, longwave radiation, shortwave radiation, and vertical diffusion heating rates. All the datasets used by this study have been regridded to a $2.5^{\circ} \times 2.5^{\circ}$ grid so to have the same spatial and temporal resolution as the ERA-Interim. We focus on boreal spring (MAM). The seasonal mean anomalies are calculated from the monthly data during MAM after removing the monthly-mean climatology based on each period, and then the trend also is removed for each segment. The statistical significance test was calculated based on a Student's $t$ test. The effective degrees of freedom to calculate the statistical significance were obtained from Livezey and Chen (1983).

To examine how much SST tendency influences the relationship between SST and precipitation, a budget analysis is performed (see Figs. 4 and 5). The SST tendency is calculated using centered differencing; that is, the SST tendency at a specific month is obtained as the difference of SST in the succeeding month minus that in the preceding month. The mixed layer heat content is dependent on air-sea heat fluxes and heat advection by ocean currents and small-scale mixing. The temperature equation can be derived as follows:

$$
\begin{aligned}
\partial_{t} T^{\prime}= & Q_{\mathrm{SW}}^{\prime}+Q_{\mathrm{LW}}^{\prime}+Q_{L}^{\prime}+Q_{S}^{\prime}-u^{\prime} \partial_{x} \bar{T} \\
& -v^{\prime} \partial_{y} \bar{T}-w^{\prime} \partial_{z} \bar{T}-\bar{u} \partial_{x} T^{\prime}-\bar{v} \partial_{y} T^{\prime} \\
& -\bar{w} \partial_{z} T^{\prime}-u^{\prime} \partial_{x} T^{\prime}-v^{\prime} \partial_{y} T^{\prime}-w^{\prime} \partial_{z} T+\text { mixing }
\end{aligned}
$$

where overbars and primes indicate monthly climatology and anomaly, respectively; $Q_{\mathrm{SW}}$ is the net shortwave radiation, $Q_{\mathrm{LW}}$ is the net longwave radiation, $Q_{L}$ is the latent heat flux, and $Q_{S}$ is the sensible heat flux; surface heat flux terms are computed from ERA-Interim data and oceanic temperature and advection terms are computed from GODAS data. Also, $u, v$, and $T$ indicate zonal 
current, meridional current, and oceanic temperature averaged over the mixed layer (top $55 \mathrm{~m}$ for $1980-98$ and $65 \mathrm{~m}$ for 1999-2014). Vertical velocity $w$ is calculated near the bottom of the mixed layer. The mixed layer depth is defined as the depth where the temperature deviation from the surface temperature is less than $0.8^{\circ} \mathrm{C}$. This budget analysis is similar to that of Kang et al. (2001). The oceanic mixing term is defined as the difference between the SST tendency term ( $\partial \mathrm{SST} / \partial t)$ and [surface net heat flux $\left(Q_{\text {net }} / \rho C_{p} D\right)$ and oceanic advection] terms following a previous study (Screen et al. 2010).

\section{Characteristics and mechanism of the episodic change}

Figure 2a shows time series of MAM anomalous SST and precipitation in the WTP for 1980-2017. To illustrate the decadal variation of the SST-precipitation relationship, Fig. 2b displays the 11-yr moving correlation coefficients of SST-precipitation in the WTP during MAM for 1980-2017. The positive SST-precipitation relationship varies substantially. A significant positive correlation (above 0.7) is observed except from the late 1990 s to the early 2010s regardless of the dataset used. During 1999-2014, the correlation coefficient of the SST-precipitation relation is only about 0.4 , which is not statistically significant. Note that such a result is captured in other window lengths (13 and $15 \mathrm{yr}$ ) and an episodic weakening in the SST-precipitation relationship like boreal spring is not observed in other seasons (figure not shown).

To understand the varying MAM SST-precipitation relationship, we calculate the lead-lag correlations of local SST-precipitation relationship in the WTP (Fig. 3a). Strongly positive correlations of SST and precipitation appear not only at lag 0 , but also at leads of 1-2 months; the maximum positive correlation is observed when the SST leads precipitation. This indicates that SST forcing on the atmosphere dominates negative atmospheric feedbacks. The positive SST-precipitation relationship during 1980-98 is also quite similar to that of the whole period (1980-2017) (Fig. 3b). As mentioned above, however, the SST-precipitation relationship weakens from the late 1990s to the early 2010s (see Fig. 2b). For 1999-2014, strongly positive correlations of SST and precipitation only appear at leads of 1-2 months when the SST leads precipitation (Fig. 3c). This indicates that the SST forcing on the atmosphere weakens or that the processes that damp SST strengthen, or both. The processes that may damp SST include atmospheric convection by increasing cloud, increasing wind-induced oceanic mixing/upwelling, or the wind-evaporation effect. We divide the data into two periods to examine the
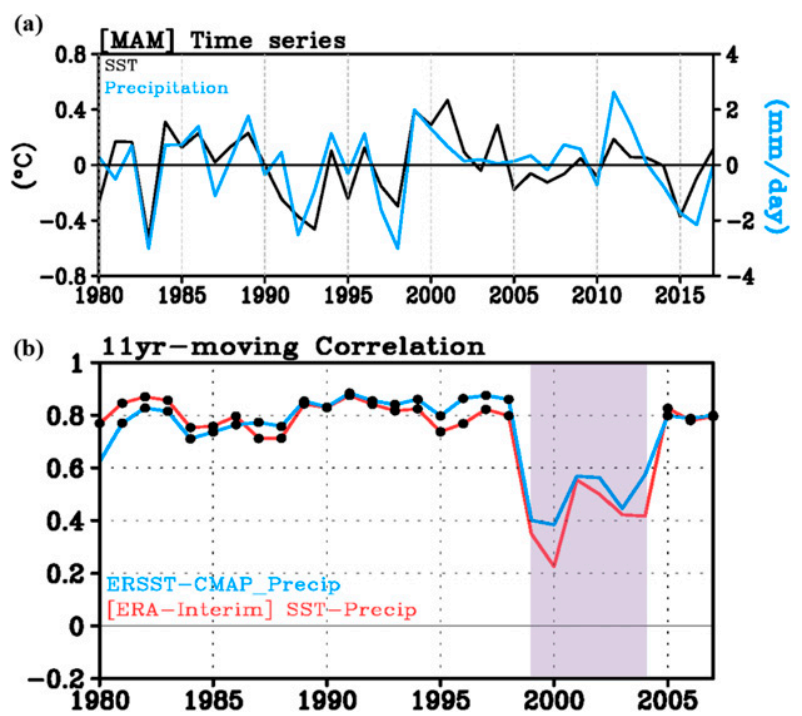

FIG. 2. (a) Time series of anomalous SST $\left({ }^{\circ} \mathrm{C}\right.$; black line) and precipitation ( $\mathrm{mm} \mathrm{day}^{-1}$; blue line) in the WTP for 1980-2017 during MAM. (b) The 11-yr moving correlation coefficients between SST and precipitation in the WTP during MAM using different datasets (blue: ERSST version 5 vs CMAP precipitation; red: ERA-Interim SST-precipitation) for 1980-2017. The $x$ axis indicates the start year in the 11-yr moving window, (e.g., 1999 indicates the correlation coefficient for 1999-2009). Dots denote the statistical significance at the $95 \%$ confidence level based on the Student's $t$ test. The purple box indicates a nonstatistical significance period.

characteristics of ocean-atmosphere interaction and their associated physical processes: 1980-98 and 1999_ 2014.

\section{a. Strong SST-precipitation relationship during 1980-98}

We regress MAM circulation fields onto a normalized January-April (JFMA) SST time series averaged over the WTP for the period of 1980-98 (Figs. 4a-f). Following $\mathrm{Wu}$ and Kirtman (2007), the regressed surface heat fluxes, oceanic advection, and oceanic mixing terms have been converted to the same units as the SST tendency $\left({ }^{\circ} \mathrm{C}\right.$ month $^{-1}$ ) to quantitatively estimate a contribution to the SST tendency. The JFMA warm SST anomalies induce positive precipitation (Fig. 4a, red) and low pressure (Fig. 4b, blue) anomalies over the WTP. The strongest low pressure is located to the northwest of the positive rainfall, which leads to southwesterly wind anomalies in the WTP, indicating a typical Gill-type forcing response (Gill 1980). The associated enhanced convection reduces the incoming shortwave radiation into the ocean surface through increased cloud (Figs. 4c,d), contributing to a negative SST tendency, which dampens the initial SSTs (Figs. 4e,f), similar to that of $\mathrm{He}$ et al. (2017) (see their Fig. 6). Overall, there is a positive SST-precipitation relationship, despite a negative SST tendency-precipitation 
[1980 - 2017]

(a) Leag-Lag SST-P Corr.

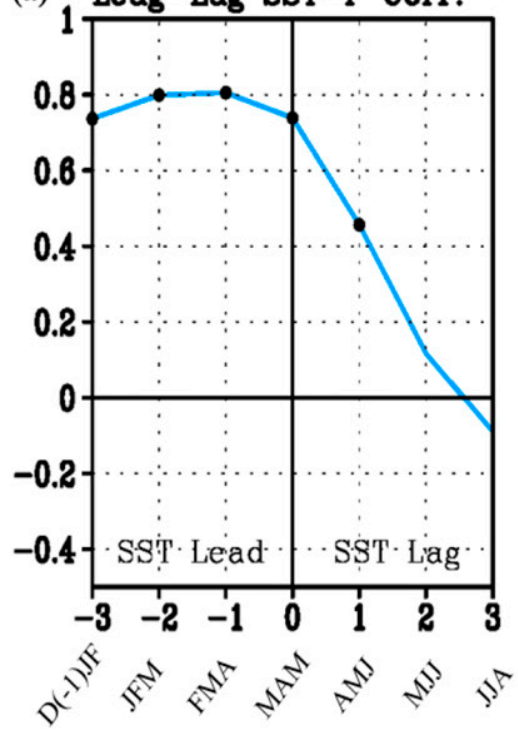

[1980 - 1998]

(b) Leag-Lag SST-P Corr.

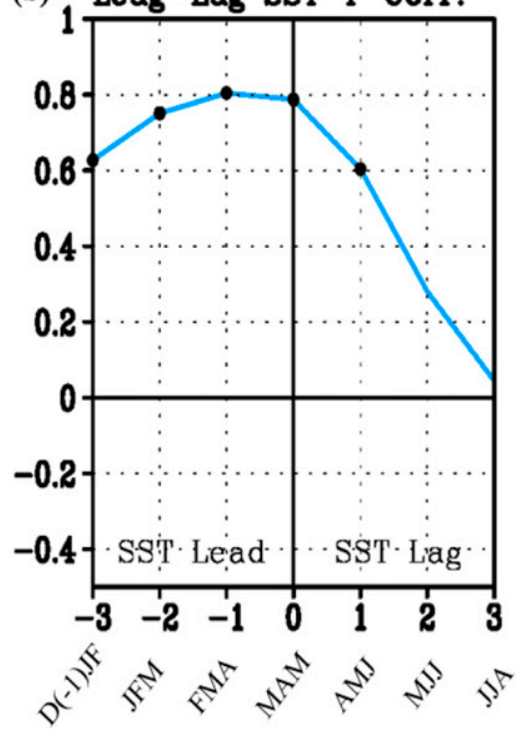

[1999-2014]

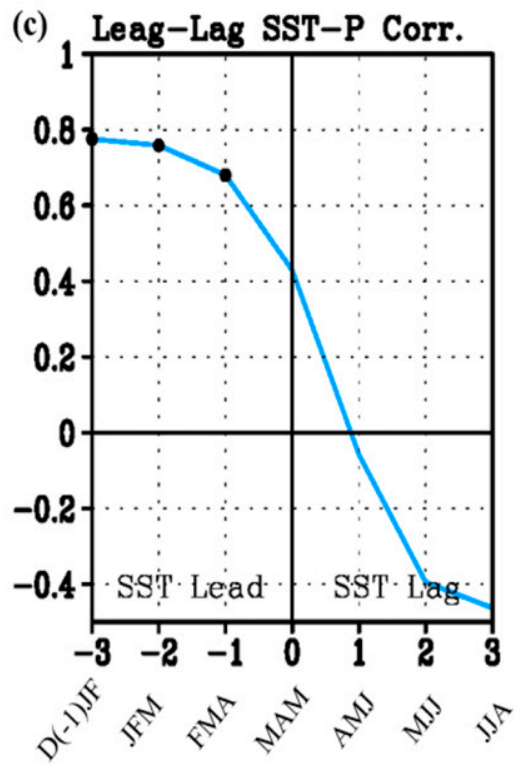

FIG. 3. (a) Lead-lagged correlations of SST and precipitation in the WTP during MAM for 1980-2017. (b),(c) As in (a), but for 1980-98 and 1999-2014, respectively. Dots denote the statistical significance at the 95\% confidence level based on the Student's $t$ test.

correlation, consistent with previous studies $(\mathrm{Wu}$ and Kirtman 2007; He et al. 2017).

To examine the details of how much decreased shortwave radiation contributes to the SST tendency, a heat budget analysis of the mixed layer temperature is performed. Figure $4 \mathrm{~g}$ shows that the shortwave radiation effect associated with the cloud-radiation effect is a leading process in governing the SST tendency in comparison with other terms. In contrast, oceanic mixing plays a secondary role, actually contributing to a positive SST tendency, albeit a weak one. This is because southwesterly wind anomalies superimposed on northeasterly mean winds (see Fig. 1b) decrease the mean wind speed in the WTP (Fig. 4b), thereby reducing oceanic mixing. In addition, the vertical advection contributes to a weak negative SST tendency, especially the thermocline feedback term $\left(-\bar{w} \partial_{z} T^{\prime}\right)$ (Fig. $\left.4 \mathrm{~g}\right)$, but the total contribution of oceanic advection is negligible. Therefore, the cloudradiation effect is a dominant process of the negative SST tendency. However, the negative SST tendency is not large enough to offset the significant positive SSTprecipitation correlation. This indicates that SST forcing on the atmosphere dominates for 1980-98.

\section{b. Weak SST-precipitation relationship during 1999-2014}

Similar to the 1980-98 period, warm SST anomalies during JFMA can induce positive precipitation with low pressure during MAM in the 1999-2014 period
(Figs. 5a,b). The associated enhanced convection dampens warm SST anomalies by reflecting incoming shortwave radiation through the cloud-radiation effect (Figs. 5c,d). However, the cooling tendency due to reduced incoming shortwave radiation is weaker (Fig. $5 \mathrm{~g}$ ) than that in the 1980-98 period. This might be related to slightly westward shifted convection associated with westward shifted SST anomalies in the central-toeastern tropical Pacific, compared to that during 198098 (Guo et al. 2016). That is, the cloud-radiation effect is weakened. Despite this, the total negative SST tendency is greater during 1999-2014 than during 1980-98.

Anomalous oceanic mixing, which contributes to a SST warming tendency during 1980-98, becomes negligible during 1999-2014 (Fig. 5g). Southwesterly wind anomalies in the WTP are not as efficient in decreasing the mean wind speed as in the 1980-98 period due to westward shifted cyclonic circulation anomalies (Fig. 5b), leading to a negligible contribution from oceanic mixing. On the other hand, the oceanic advection, especially the vertical advection (e.g., $-\bar{w} \partial_{z} T^{\prime}$ and $-w^{\prime} \partial_{z} \bar{T}$ ), becomes a stronger contribution to the SST cooling tendency (Fig. 5g), which is associated with surface wind change (Fig. 5b); enhanced easterly wind anomalies in the southern part of the WTP are observed, leading to enhanced oceanic upwelling. Thus, the cloud-radiation effect acts in concert with oceanic advection, both favoring a larger SST cooling tendency. The enhanced SST cooling tendency compared to that during 1980-98 
[1980 - 1998]

(a) Precip. $/ 3$

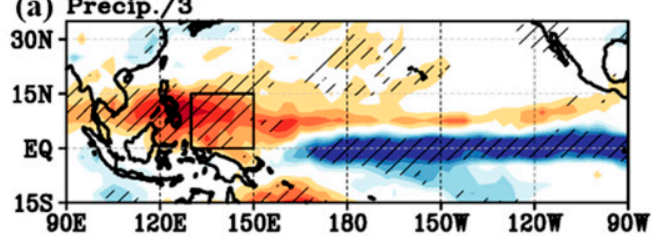

(b) SLP $/ 2$ \& Wind stress

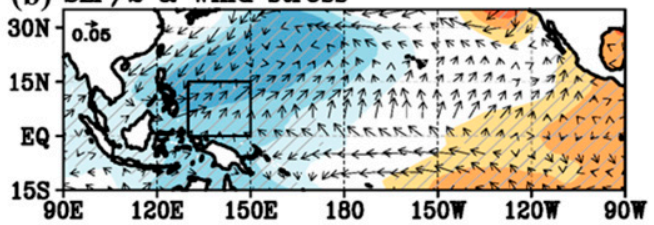

(c) Total cloud cover*5

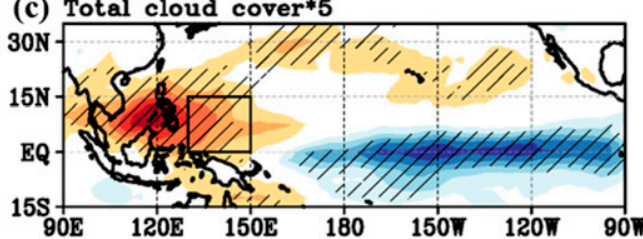

(d) $\mathrm{SW} * 3$

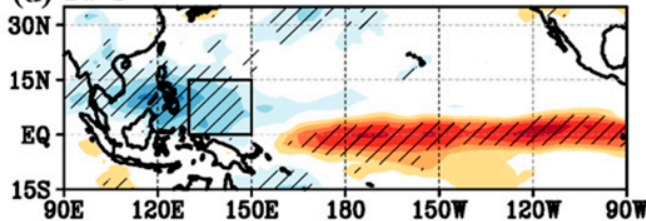

(e) SST tendency*3

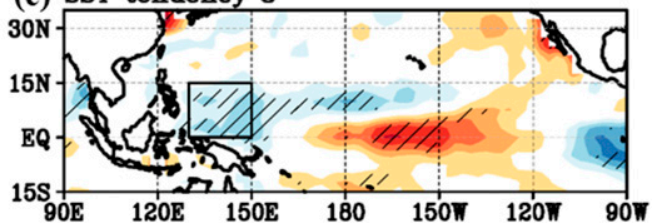

(f) SST

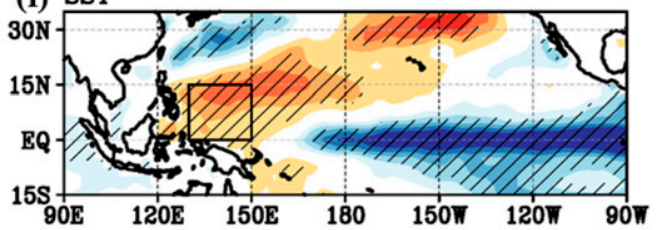

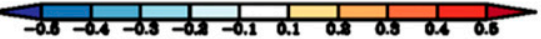

(g) Mixed layer heat budget

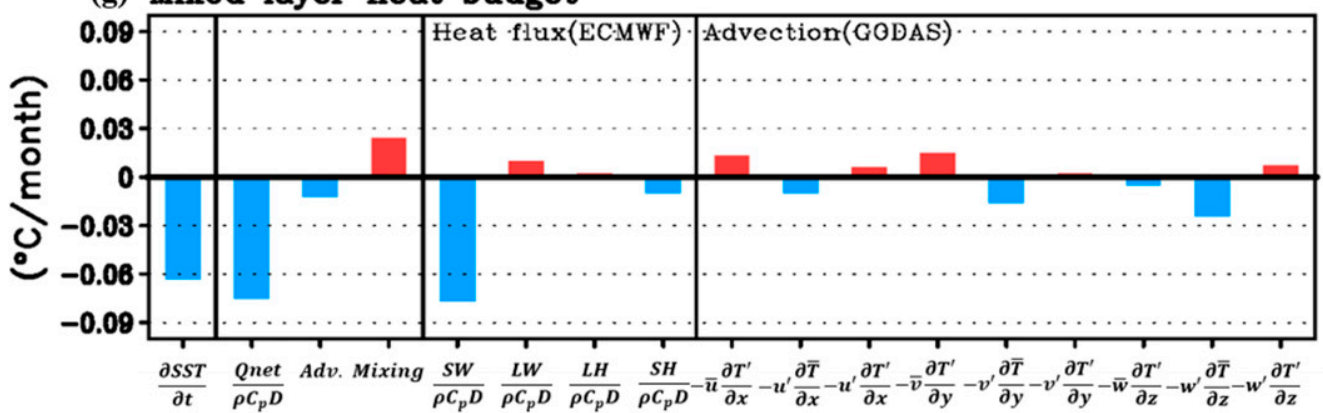

FIG. 4. (a) Lagged regression of precipitation (shading; $\mathrm{mm}^{-1 a y}{ }^{-1}$ ), (b) sea level pressure (SLP) (shading; hPa) and wind stress (vectors; $\mathrm{N} \mathrm{m}^{-2}$ ), (c) total cloud cover (\%), (d) surface shortwave radiation $(\mathrm{SW})\left({ }^{\circ} \mathrm{C} \mathrm{month}^{-1}\right)$, (e) SST tendency $\left({ }^{\circ} \mathrm{C}\right.$ month $\left.{ }^{-1}\right)$, (f) SST $\left({ }^{\circ} \mathrm{C}\right)$ anomalies, and $(\mathrm{g})$ area-averaged mixed layer heat budget for each terms in the WTP during MAM against normalized SST in the WTP during JFMA for 1980-98. The negative values indicate that decreasing heat flux into the ocean. The hatching denotes the region where statistical significance is above the $95 \%$ confidence level based on the Student's $t$ test. Note that rescaling has been applied in showing the regression coefficients, which is indicated at the top of the respective panel. Regression coefficients are per standardized change in the WTP SST.

dampens the initial SSTs quickly, resulting in a weakening of the SST-precipitation relationship during 19992014.

\section{Implications for regional climate}

In terms of mean state change, the PDO has shifted to its negative phase since the late 1990s with enhanced easterlies along the equatorial Pacific (England et al. 2014; Lyon et al. 2014; McGregor et al. 2014; Trenberth et al. 2014). As a result, precipitation is enhanced over the WTP. In addition, diabatic heating is intensified throughout the WTP troposphere after the late 1990s (Fig. 6a). These features are accompanied by uppertropospheric teleconnection wave patterns that extend throughout the Pacific (Trenberth et al. 2014). On the other hand, the decreased precipitation variance in the 1999-2014 period (Fig. 2a) leads to a reduction in the sensitivity of precipitation to the SST forcing and modifies atmospheric heating structure, potentially modulating the tropical-extratropical teleconnection patterns (Alexander et al. 2002). 


\section{[1999-2014]}
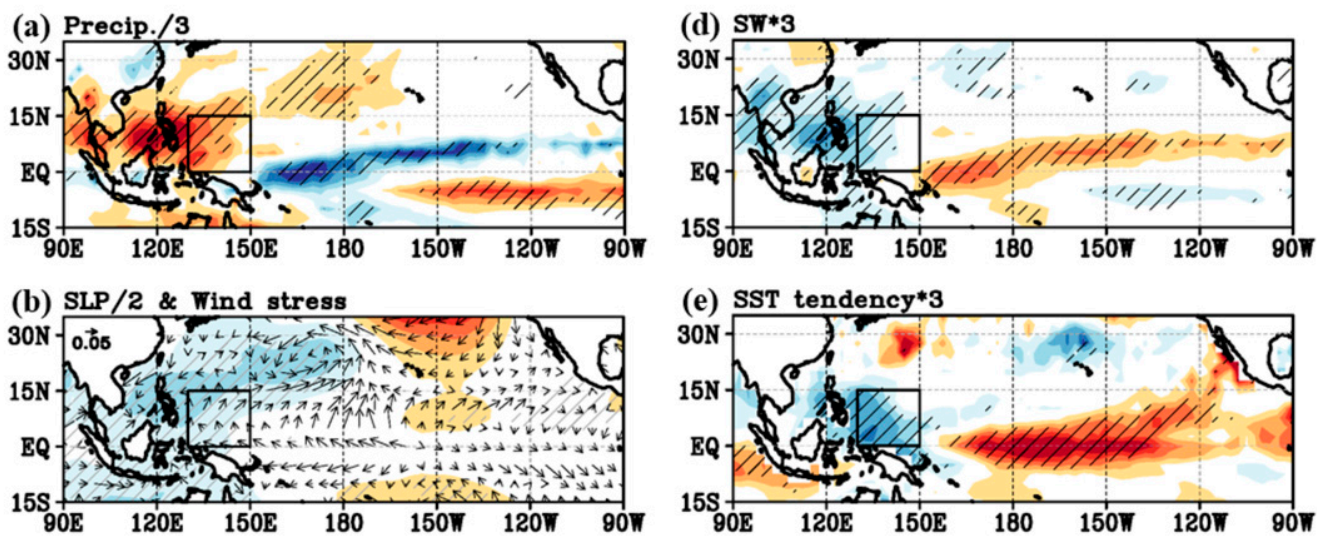

(c) Total cloud cover*5

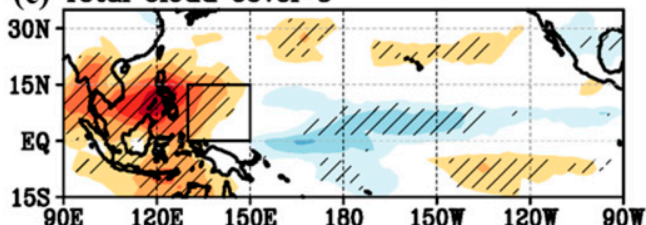

(f) SST
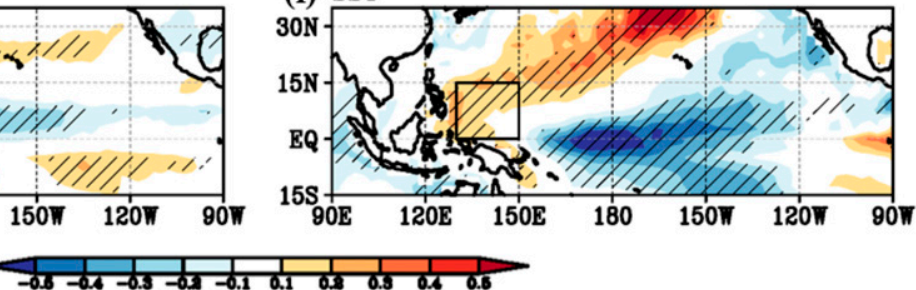

(g) Mixed layer heat budget

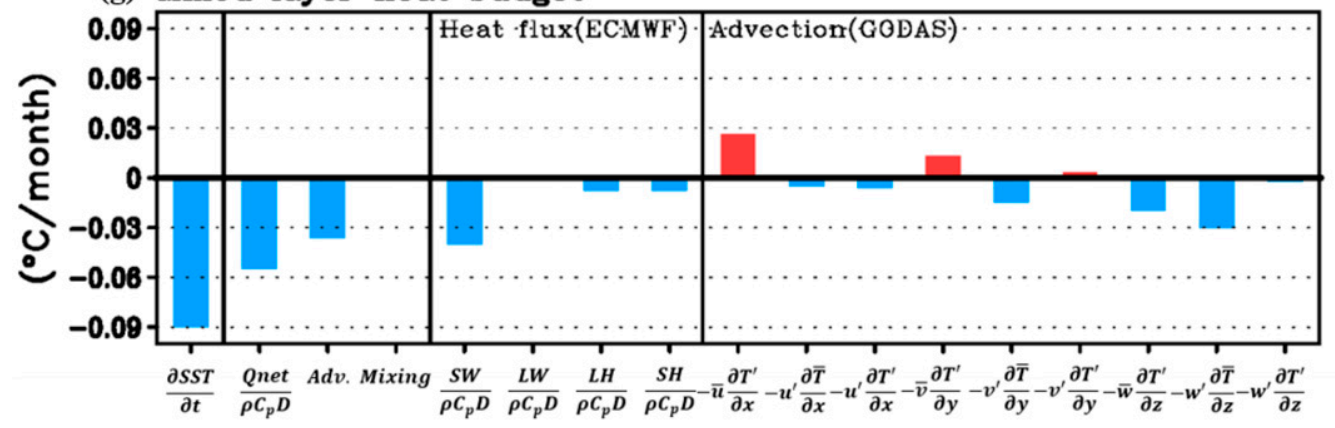

FIG. 5. As in Fig. 4, but for 1999-2014.

Figure $6 \mathrm{~b}$ depicts the regression patterns of diabatic heating profile, $2-\mathrm{m}$ air temperature, and $200-\mathrm{hPa}$ geopotential anomalies associated with a time series of normalized SST anomaly in the WTP for 1980-98. The area-averaged vertical profiles of diabatic heating show a significant heating throughout most of the troposphere (Zhang and Hagos 2009). Because Rossby wave source of tropical divergence is induced by tropical convective heating (Sardeshmukh and Hoskins 1988, Yeh et al. 2018), spatial patterns of the regressed geopotential anomalies indicate a typical structure of Rossby waves propagating downstream over the North Pacific to North America (Fig. 6b). As a result, the regressed surface air temperature anomaly pattern reveals a significant warming in the southwestern, but a cooling in the northwestern part of North America, and a warming in northeastern Eurasia (Fig. 6b). Conversely, the WTP convective heating associated with SSTs weakens in the post-1999 period (Fig. 6c) due to the weakening of precipitation sensitivity to the SST forcing. As a result, the tropical-extratropical teleconnection patterns changed. In addition, warm or cool surface air temperature anomalies in North America and northeastern Eurasia are reduced. Thus, the results in Fig. 6 indicate that even though the total WTP precipitation increases in the post-1999 period, the decreased sensitivity of precipitation to the SST forcing in the 1999-2014 period modifies atmospheric heating structure and the tropical-extratropical teleconnection patterns, affecting surface air temperature 


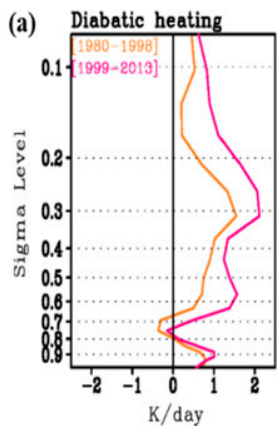

Diff. Precip. and Z200

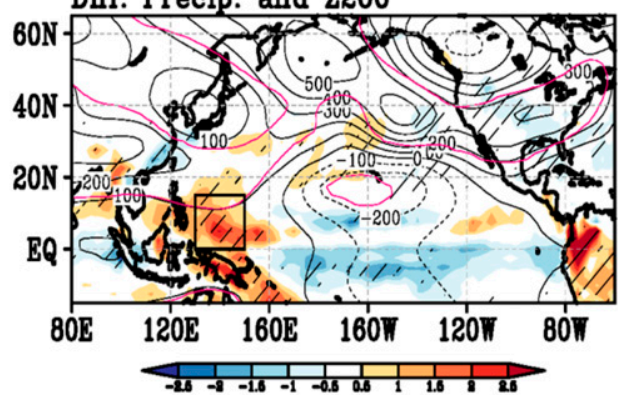

$[1980-1998]$

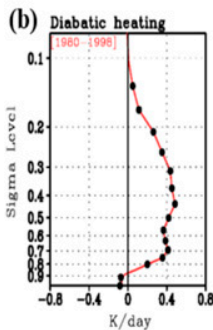

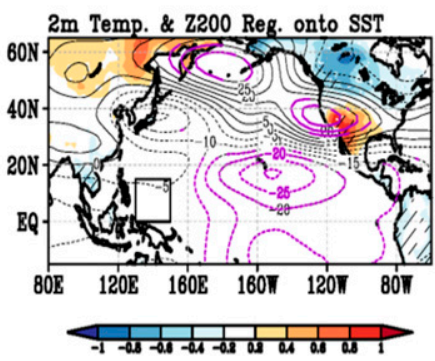

[1999 - 2014]

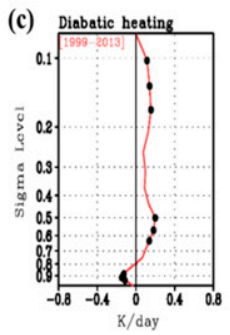

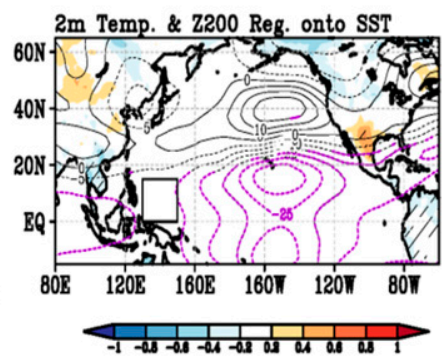

FIG. 6. (a) Area-averaged vertical profiles of diabatic heating $\left(\mathrm{K} \mathrm{day}^{-1}\right)$ in the WTP for 1980-98 and 1999-2014 and difference in the mean precipitation (shading; $\mathrm{mm} \mathrm{day}^{-1}$ ) and 200-hPa geopotential height (contours; $\mathrm{m}$ ) in Pacific rim during MAM (1999-2014 minus 1980-98). (b) Lagged regressions of area-averaged vertical profile of diabatic heating $\left(\mathrm{K} \mathrm{day}^{-1}\right)$ in the WTP, 2-m air temperature (K), and 200-hPa geopotential height (m) anomalies during MAM against normalized SST anomaly in the WTP during JFMA for 1980-98. (c) As in (b), but for 19992014 and for diabatic heating (1999-2013). The dots, hatching, and purple line denote the region where statistical significance is above the $95 \%$ confidence level based on the Student's $t$ test.

anomalies in western North America and northeastern Eurasia.

\section{Summary}

A positive statistically significant correlation of MAM SST and precipitation over the WTP weakens substantially during the period from the late 1990s to the early 2010s. Such an episodic weakening in the SST-precipitation relationship has not been previously reported, including the underlying mechanisms and the associated change in atmospheric teleconnection patterns.

We found that during the 1980-98 period, warm SST anomalies in JFMA induce positive precipitation and low pressure anomalies in the WTP. The associated enhanced convection dampens the initial warm SST anomalies by reflecting incoming solar radiation through increased cloud, and vice versa. That is, reduced shortwave radiation is a leading contributor to a SST cooling tendency, but this is offset by a weak warming tendency resulting from a weaker oceanic mixing. During the 1999-2014 period, warm SST anomalies in JFMA can also induce a
SST cooling tendency, which is, however, enhanced by an anomalous ocean advection, as a result of increase easterly winds. Therefore, during 1999-2014, a cloudradiation effect acts in concert with oceanic advection to favor a large SST cooling tendency. This dampens the growth of SST anomalies and results in a weakened SSTprecipitation relationship during the 1999-2014 period.

The weakened SST-precipitation relationship decreases the sensitivity of precipitation to the SST forcing and modifies the associated atmospheric heating structure, modulating the tropical-extratropical teleconnection patterns. The diabatic heating structure based on regression onto WTP SST anomalies shows a deep convective heating profile during the 1980-98 period. As a result, the associated spatial patterns indicate a typical Rossby wave structure in the midlatitudes. Furthermore, the regressed surface air temperature anomalies reveal a significant warming in the southwestern part of North America and a warming in northeastern Eurasia. Conversely, the convective heating attributed to SST anomalies in the WTP weakens in the post-1999 period. As a result, the magnitudes of warm or cool surface air temperature anomalies in 
North America and northeastern Eurasia are reduced. Thus, the weakened SST-precipitation relationship changes the atmospheric teleconnection patterns and affects regional climate in the midlatitudes. Our study highlights the importance of understanding the change in oceanatmosphere interactions on decadal time scales and how these changes may impact regional climate.

Acknowledgments. SWY was funded by the Korea Meteorological Administration Research and Development Program under Grant KMI2018-03211. This work is supported by the Centre for Southern Hemisphere Oceans Research, a joint research center between QNLM and CSIRO.

\section{REFERENCES}

Alexander, M. A., I. Bladé, M. Newman, J. R. Lanzante, N.-C. Lau, and J. D. Scott, 2002: The atmospheric bridge: The influence of ENSO teleconnections on air-sea interaction over the global oceans. J. Climate, 15, 2205-2231, https://doi.org/10.1175/15200442(2002)015<2205:TABTIO >2.0.CO;2.

Behringer, D., and Y. Xue, 2004: Evaluation of the global ocean data assimilation system at NCEP: The Pacific Ocean. Eighth Symp. on Integrated Observing and Assimilation Systems for Atmosphere, Oceans, and Land Surface, Seattle, WA, Amer. Meteor. Soc., 2.3, https://ams.confex.com/ams/84Annual/techprogram/ paper_70720.htm.

Chang, E.-C., S.-W. Yeh, S. Hong, and R. Wu, 2011: The role of airsea interactions in the in-phase transitions of the Indian-toAustralian summer monsoon. J. Geophys. Res., 116, D01107, https://doi.org/10.1029/2010JD014522.

,-- , S.-Y. Hong, J.-E. Kim, R. Wu, and K. Yoshimura, 2014: Study on the changes in the East Asian precipitation in the mid-1990s using a high-resolution global downscaled atmospheric data set. J. Geophys. Res. Atmos., 119, 2279-2293, https://doi.org/10.1002/2013JD020903.

Dee, D. P., and Coauthors, 2011: The ERA-Interim reanalysis: Configuration and performance of the data assimilation system. Quart. J. Roy. Meteor. Soc., 137, 553-597, https://doi.org/ 10.1002/qj.828.

England, M. H., and Coauthors, 2014: Recent intensification of wind-driven circulation in the Pacific and the ongoing warming hiatus. Nat. Climate Change, 4, 222-227, https://doi.org/ 10.1038/nclimate2106.

Gill, A. E., 1980: Some simple solutions for heat-induced tropical circulation. Quart. J. Roy. Meteor. Soc., 106, 447-462, https:// doi.org/10.1002/qj.49710644905.

Guo, Y., Z. Wen, and R. Wu, 2016: Interdecadal change in the tropical Pacific precipitation anomaly pattern around the late 1990s during boreal spring. J. Climate, 29, 5979-5997, https:// doi.org/10.1175/JCLI-D-15-0462.1.

He, Z., R. Wu, W. Wang, Z. Wen, and D. Wang, 2017: Contributions of surface heat fluxes and oceanic processes to tropical SST changes: Seasonal and regional dependence. J. Climate, 30, 4185-4205, https://doi.org/10.1175/JCLI-D-16-0500.1.

Huang, B., and Coauthors, 2015: Extended reconstructed sea surface temperature version 4 (ERSST. v4). Part I: Upgrades and intercomparisons. J. Climate, 28, 911-930, https://doi.org/ 10.1175/JCLI-D-14-00006.1.
Huang, R., and F. Sun, 1992: Impacts of the tropical western Pacific on the East Asian summer monsoon. J. Meteor. Soc. Japan, $\mathbf{7 0}$, 243-256, https://doi.org/10.2151/jmsj1965.70.1B_243.

Jang, H.-Y., S.-W. Yeh, E.-C. Chang, and B.-M. Kim, 2016: Evidence of the observed change in the atmosphere-ocean interactions over the South China Sea during summer in a regional climate model. Meteor. Atmos. Phys., 128, 639-648, https://doi.org/10.1007/s00703-016-0433-5.

Jo, H.-S., S.-W. Yeh, and S.-K. Lee, 2015: Changes in the relationship in the SST variability between the tropical Pacific and the North Pacific during the 1998/99 regime shift. Geophys. Res. Lett., 42, 7171-7178, https://doi.org/10.1002/ 2015 GL065049.

Kanamitsu, M., and Coauthors, 2002: NCEP dynamical seasonal forecast system 2000. Bull. Amer. Meteor. Soc., 83, 1019-1038, https://doi.org/10.1175/1520-0477(2002)083<1019: NDSFS $>2.3 . \mathrm{CO} ; 2$.

Kang, I.-S., S.-I. An, and F.-F. Jin, 2001: A systematic approximation of the SST anomaly equation for ENSO. J. Meteor. Soc. Japan, 79, 1-10, https://doi.org/10.2151/jmsj.79.1.

Kim, J.-E., S.-W. Yeh, and S.-Y. Hong, 2009: Two types of strong northeast Asian summer monsoon. J. Climate, 22, 4406-4417, https://doi.org/10.1175/2009JCLI2434.1.

Kumar, A., M. Chen, and W. Wang, 2013: Understanding prediction skill of seasonal mean precipitation over the tropics. J. Climate, 26, 5674-5681, https://doi.org/10.1175/JCLI-D-1200731.1.

Lee, E.-J., S.-W. Yeh, J.-G. Jhun, and B.-K. Moon, 2006: Seasonal change in anomalous WNPSH associated with the strong East Asian summer monsoon. Geophys. Res. Lett., 33, L21702, https://doi.org/10.1029/2006GL027474.

Livezey, R. E., and W. Chen, 1983: Statistical field significance and its determination by Monte Carlo techniques. Mon. Wea. Rev., 111, 46-59, https://doi.org/10.1175/1520-0493(1983)111<0046: SFSAID $>2.0 . \mathrm{CO} ; 2$.

Lu, R., and S. Lu, 2014: Local and remote factors affecting the SSTprecipitation relationship over the western North Pacific during summer. J. Climate, 27, 5132-5147, https://doi.org/ 10.1175/JCLI-D-13-00510.1.

Lyon, B., and D. G. DeWitt, 2012: A recent and abrupt decline in the East African long rains. Geophys. Res. Lett., 39, L02702, https://doi.org/10.1029/2011GL050337.

—, A. G. Barnston, and D. G. DeWitt, 2014: Tropical Pacific forcing of a 1998-1999 climate shift: Observational analysis and climate model results for the boreal spring season. Climate Dyn., 43, 893-909, https://doi.org/10.1007/s00382-013-1891-9.

McGregor, S., A. Timmermann, M. F. Stuecker, M. H. England, M. Merrifield, F.-F. Jin, and Y. Chikamoto, 2014: Recent Walker circulation strengthening and Pacific cooling amplified by Atlantic warming. Nat. Climate Change, 4, 888-892, https:// doi.org/10.1038/nclimate2330.

Nitta, T., 1987: Convective activities in the tropical western Pacific and their impact on the Northern Hemisphere summer circulation. J. Meteor. Soc. Japan, 65, 373-390, https://doi.org/ 10.2151/jmsj1965.65.3_373.

Sardeshmukh, P. D., and B. J. Hoskins, 1988: The generation of global rotational flow by steady idealized tropical divergence. J. Atmos. Sci., 45, 1228-1251, https://doi.org/10.1175/15200469(1988)045<1228:TGOGRF>2.0.CO;2.

Screen, J. A., N. P. Gillett, A. Y. Karpechko, and D. P. Stevens, 2010: Mixed layer temperature response to the southern annular mode: Mechanisms and model representation. J. Climate, 23, 664-678, https://doi.org/10.1175/2009JCLI2976.1. 
Trenberth, K. E., J. T. Fasullo, G. Branstator, and A. S. Phillips, 2014: Seasonal aspects of the recent pause in surface warming. Nat. Climate Change, 4, 911-916, https://doi.org/10.1038/nclimate2341.

Wang, B., R. Wu, and K. Lau, 2001: Interannual variability of the Asian summer monsoon: Contrasts between the Indian and the western North Pacific-East Asian monsoons. J. Climate, 14, 4073-4090, https://doi.org/10.1175/1520-0442(2001) 014<4073:IVOTAS $>2.0 . \mathrm{CO} ; 2$.

— - _ and T. Li, 2003: Atmosphere-warm ocean interaction and its impacts on Asian-Australian monsoon variation. J. Climate, 16, 1195-1211, https://doi.org/10.1175/1520-0442(2003)16<1195: AOIAII $>2.0 . \mathrm{CO} ; 2$.

Wu, B., T. Zhou, and T. Li, 2009: Contrast of rainfall-SST relationships in the western North Pacific between the ENSOdeveloping and ENSO-decaying summers. J. Climate, 22, 4398-4405, https://doi.org/10.1175/2009JCLI2648.1.

Wu, R., and B. P. Kirtman, 2007: Regimes of seasonal air-sea interaction and implications for performance of forced simulations. Climate Dyn., 29, 393-410, https://doi.org/10.1007/s00382-007-0246-9. and K. Pegion, 2006: Local air-sea relationship in observations and model simulations. J. Climate, 19, 4914-4932, https://doi.org/10.1175/JCLI3904.1.

Xie, P., and P. A. Arkin, 1997: Global precipitation: A 17-year monthly analysis based on gauge observations, satellite estimates, and numerical model outputs. Bull. Amer. Meteor. Soc., 78, 2539-2558, https://doi.org/10.1175/1520-0477(1997)078<2539: GPAYMA $>2.0 . \mathrm{CO} ; 2$

Yeh, S.-W., and Coauthors, 2018: ENSO atmospheric teleconnections and their response to greenhouse gas forcing. Rev. Geophys., 56, 185-206, https://doi.org/10.1002/2017RG000568.

Yim, S.-Y., S.-W. Yeh, R. Wu, and J.-G. Jhun, 2008: The influence of ENSO on decadal variations in the relationship between the East Asian and western North Pacific summer monsoons. J. Climate, 21, 3165-3179, https://doi.org/10.1175/ 2007JCLI1948.1.

Zhang, C., and S. M. Hagos, 2009: Bi-modal structure and variability of large-scale diabatic heating in the tropics. J. Atmos. Sci., 66, 3621-3640, https://doi.org/10.1175/2009JAS3089.1. 